ton's hypothesis they should be double, as he finds them to be in Tradescantia and other forms.

Catcheside's very interesting case ${ }^{4}$ of a triploid Enothera with its 21 chromosomes all arranged endto-end in the spireme to form a closed ring is, if correct, a fatal blow to Darlington's theories as applied to Enothera, as he has admitted. Having admitted so much, he now denies the facts, but Mr. Catcheside's preparations have been examined by other cytologists besides myself, and we were agreed that his interpretation is correct, although the evidence is not, perhaps, so copious as one would like. Moreover, the usual distribution of the chromosomes as $10+11$ in the reduction division, which $I$ first showed in $1909,{ }^{5}$ and Catcheside has recently confirmed, is the result which would be expected from a ring of 21 linked chromosomes with successive members oriented towards opposite poles. The early conclusion of mine ${ }^{5}$ which Darlington quotes, "that there is usually no metaphase, strictly speaking", in Enothera, has been abundantly confirmed by the work of many subsequent investigators, the zigzag arrangement of the chromosomes at this time being in marked contrast to their usual alinement.

Cleland (who has also described telosynapsis in many (Enothera forms) and Blakeslee ${ }^{6}$ have recently shown that the rings of chromosomes in many Enothera species have a possible explanation on the basis of segmental interchange according to Blakeslee and Belling's hypothesis for Datura. While such comparisons are to be welcomed as representing a possible advance, there are, nevertheless, important differences between the two genera, and in any case in recent years there has been evidence to suggest (in such papers as that of Latter on Lathyrus) that segmental interchange can also take place in connexion with telosynapsis and not merely as the result of lateral pairing of threads. Blakeslee and Belling's hypothesis of segmental interchange is therefore quite independent of parasynapsis, and there is no reason why its occurrence in Enothera should be regarded as an indication of lateral pairing.

Whether my work on Enothera during the last twenty years and more has been "sterile" can safely be left to others to judge. Those who wish to form an unbiased opinion should read Lehmann's "Die Theorien der Enotheraforschung "(Fischer, 1922), which deals with the whole subject up to 1922 . They will then be able to realise the important part which the cytological investigations of $Q E$ nothera have played in the history of genetics. A more recent monograph (Gates, $1928^{7}$ ) deals also with some of the later work. My first critical paper on the subject 8 showed a telosynaptic course of events, contrary to my anticipations at that time, and of the scores of papers on the subject published since, every critical one has repeated the same story in all essentials, though with varying details and additional facts. Especially has the constancy of chromosome linkages been brought out in recent years. Various parasynaptists have endeavoured to make the facts fit into their ideas, but without conspicuous success. Notably the Gregoire school have investigated $C_{\text {Enother }},{ }^{9}$ but failed completely to find evidence of parasynapsis. They could only repeat in its essentials the telosynaptic account. Recently Weier ${ }^{10}$ has made another attempt. But anyone who examines his figures, for example, Figs. 18-22 and 36-39, will see that the special method of fixation which he recommends has been anything but a success, with the result that the chromatin has flowed together to form what he calls the "central coagulum", which is obviously not a natural condition.

The idea that all organisms must conform to one scheme of pairing has seriously retarded progress in this field. There are signs that some of the younger cytologists are developing less stereotyped ideas on this subject.

King's College,

R. Ruggles Gates.

London, May 19.

1 Gates, Bot. Gaz., 51, 321.

Ibid., 41, 799; Proc. Roy. Soc., 105, 207; also Gates and Sheflield,

Proc. Roy. Soc., 105, 499 .

Proc. Roy. Soc., 105, 499.

5 Bot. Gaz., 48, $179 ; 1909$.

Proc. Nat. Acad. Sci., 16, 1930.

Bibliographia Genetica, 4, 401-492.

Bot. Gaz., 46, 1 ; 1908

See Vancanover, La Cellule, 37, 203-225 : 1927.

10 La Cellule, 39, 271 ; 1930.

\section{Interpretation of Infra-Red Frequencies of the Diamond.}

Nature of May 10 contains two interesting communications - one by Robertson and Fox and another by Ramaswamy-on the infra-red frequencies of the diamond, as determined directly and as inferred from the Raman effect. With the view of interpreting these lines, it appears to me to be of interest that attention be directed to the following facts :

Some time ago (Sitzungsberichte der Preuss. Akad. der Wiss., 33, 447; 1926), from an analysis of the change of the specific heat with temperature, I had concluded that the atoms of a number of crystallised substances are capable of assuming two states differing in energy to so small an extent that the higher quantum state is excited thermally at comparatively low temperatures. The diamond is one of these substances. Formerly, the attempt was made to interpret its specific heat with the help of a Debye function of $\theta=1860$; but now a much better agreement with the experimental results is found by means of a Debye function of $\theta=2340$ and the supposition that the $\mathrm{C}$-atoms can assume two states differing in energy by 2120 calories per mol.

If we therefore desire to compare the infra-red lines with the thermal data, we must consider not only the altered frequency but also the possibility that the higher quantum state can be excited by light. From the above-mentioned energy difference a wave-length of $13.4 \mu$ can be calculated (experimental error about 10 per cent). Reinkober has, in fact, found an absorption band at $14 \mu$. Now Ramaswamy believes he has discovered a diffuse band which can be calculated to correspond to a wave-length of about 15-16 $\mu$. Taking the experimental error into account, which may be considerable in these Raman measurements, it is quite possible that this diffuse band is due to the transition to the higher quantum state brought about by the action of light. Whether this is actually the case could be determined first by a more accurate determination and discussion of the infra-red bands, and in the second place by determining the variation of the intensity of the lines with temperature, for which a perfectly definite course would be prescribed by the above-mentioned interpretation.

I may mention that the existence of an X-ray reflection from the 222 plane of the diamond may be connected with these two energy states of the $\mathrm{C}$-atom, and moreover that, in the case of silicon and grey tin, both having the same crystal structure as the diamond, the specific heats point very definitely to the same phenomenon.

F. SIMoN. Physikalisch-chemisches

Institut der Universität, Berlin, May 24.

No. 3162, VoL. 125] 